\title{
LÍNGUA E CULTURA NA FEMINIZAÇÃO DAS MIGRAÇÕES NO BRASIL'
}

\section{LANGUAGE AND CULTURE IN THE FEMINIZATION OF MIGRATION IN BRAZIL}

\section{Ana Cristina Balestro* Telma Pereira**}

\section{RESUMO}

O presente artigo tem por objetivo geral refletir sobre língua e cultura no contexto da "feminização das migrações" (CORTES, 2016; MARINUCCI, 2007; MEJIA; CAZAROTTO, 2016), especificamente a migração de refúgio, pensando o fenômeno sob uma perspectiva dos estudos em Políticas Linguísticas. Ao considerar-se trajetórias de migração, entendemos que os objetivos e os desafios podem mudar conforme o gênero: segundo o Alto Comissariado das Nações Unidas para Refugiados (ACNUR) a discriminação contra as mulheres e meninas, e violências derivadas dessa, é causa e também consequência do deslocamento forçado. No Brasil, a presença feminina na imigração de refúgio se apresenta expressiva: em 2016, segundo dados da Secretaria Nacional de Justiça, as mulheres representaram mais de $30 \%$ dos que buscam acolhimento no país. Buscamos refletir sobre (i) as barreiras linguísticas na inserção social e linguística na sociedade de acolhimento, (ii) a língua e cultura de origem e aquelas de acolhimento, através de narrativas de uma refugiada em entrevistas disponíveis online. Contextualizamos a pesquisa com uma revisão bibliográfica, com dados consolidados por estudos sobre a realidade da imigração no Brasil nos últimos anos (ACNUR, CONARE, IMDH, OBMigra).

Palavras-chave: refúgio; narrativas; mulheres

\section{ABSTRACT}

This paper proposes a reflexion on the language and culture in the context of the "feminization of migrations" (CORTES, 2016; MARINUCCI, 2007; MEJIA; CAZAROTTO, 2016), specifically the refuge migration, taking the phenomenon from a study perspective in Language Policy. Considering the migration trajectories, we understand that the objectives and challenges can varydepending on gender: according to the UNHCR, discrimination against women and girls and the resulting violence is both cause and consequence of forced displacement. In Brazil, the presence of women in refugee immigration is significant: in 2016, according to data from the National Secretariat of Justice, women represented more than $30 \%$ of those seeking refugee. We seek to (i) reflect on language barriers in social and linguistic insertion in the host society, (ii) propose a reflexion on the language and culture

\footnotetext{
* Universidade Federal Fluninense (UFF), Niterói, RJ, Brasil. acbalestro@id.uff.br, https://orcid. org/0000-0002-8259-5794

** Universidade Federal Fluninense (UFF), Niterói, RJ, Brasil. tcaspereira@uol.com.br

1. O presente trabalho foi realizado com apoio da Coordenação de Aperfeiçoamento de Pessoal de Nível Superior - Brasil (CAPES) - Código de Financiamento 001
} 
of origin and those of host country, through the narratives of a woman refugee in interviews available online. We contextualize the research with a bibliographical review, with data consolidated by studies on the reality of immigration in Brazil in recent years (UNHCR, CONARE, IMDH, OBMigra).

Keywords: refugee; narratives; women

\section{INTRODUÇÃO}

Mariama Bah é uma refugiada de um país que não aparece tanto nas mídias brasileiras - como é o caso de países como a Venezuela, a Síria e o Haiti. Ela saiu sozinha da Gâmbia e buscou refúgio no Brasil - não por fome, crise ou por guerra; escolheu sair do país onde nasceu e cresceu em busca de um direito básico: educação. É a partir da história de vida dessa refugiada africana, com dados coletados em entrevistas disponíveis online, que discutimos neste artigo a feminização das migrações em contexto de refúgio, bem como as relações entre língua e cultura nesse mesmo contexto.

Aos 9 anos de idade, Mariama Bah foi retirada da escola para cumprir um arranjo de sua família: casaria ${ }^{2}$ aos 13 anos. Tornou-se mãe aos 14 anos. Atualmente com aproximadamente 30 anos, e no Brasil desde o final de 2013, conseguiu trazer sua filha após dois anos morando no país. Mariama já concluiu o ensino médio e ingressou em um curso superior no Rio de Janeiro.

De acordo com o Alto Comissariado das Nações Unidas para Refugiados (ACNUR), os motivos e objetivos de migração podem ser diferentes conforme o gênero: a agência da Organização das Nações Unidas destaca que a discriminação e a violência contra as mulheres e meninas pode causar deslocamento forçado, além de ser um dos riscos no movimento migratório. No Brasil, a presença feminina na imigração de refúgio se apresenta gradualmente mais expressiva: em 2016, segundo dados da Secretaria Nacional de Justiça, mulheres representaram mais de 30\% dos que buscaram acolhimento no país.

Compartilhamos da premissa de que situações de desigualdade enfrentadas por migrantes e refugiados são um desafio, ao mesmo passo que são fatores de exclusão e de discriminação, necessitando de políticas públicas específicas.

2. De acordo com dados disponibilizados pela UNICEF, em 17/06/2016, no ano de 2013, $41 \%$ das jovens entre 20 - 49 anos havia casado antes dos 18 anos e $16 \%$ deste grupo havia casado antes dos 15 anos. A reportagem explica que, no contexto cultural, muitas vezes os maridos são consideravelmente mais velhos do que as meninas e que, quando perguntados, os pais normalmente defendem que o matrimônio infantil evita que as filhas passem por gravidez solteiras. Disponível em: https://www.unicef.org/gambia/media_10386.html Acessado em julho de 2019. 
Políticas públicas para migrantes podem fortalecer as desigualdades, enquanto a inclusão da população migrante e refugiada nas políticas públicas pensadas em uma perspectiva integral e transversal favorece a integração e a prevenção de violações de direitos. Desigualdade não se combate com igualdade; se previne com equidade. (LUSSI, 2015, p. 136)

A questão da busca pela não discriminação e inclusão de refugiados abarca também a questão da igualdade entre gêneros, que propomos abordar sob uma perspectiva social/cultural e multidisciplinar.

A conexão entre as mulheres e a migração emergiu lentamente como uma área de pesquisa, formando hoje um campo específico de estudo que tem sido amplamente explorado na sociologia, antropologia e geografia, entre outras disciplinas. ${ }^{3}$ (CORTES, 2016, p.2, tradução nossa)

A proposta deste artigo é trazer, a partir de um recorte de gênero, uma reflexão atual sobre questões de cultura e língua no processo de integração dos refugiados. A estrutura do trabalho propõe, primeiramente, uma descrição do perfil dos refugiados no Brasil, seguido de um panorama geral da situação e das leis que os amparam na chegada ao Brasil, para apreender o contexto e dificuldades linguísticas no acolhimento. Primeiramente, adotamos uma metodologia qualitativa, fundamentada em pesquisa documental. Por ser um tema atual e com constantes mudanças e atualizações, partes dos dados são extraídas de instituições governamentais e notícias, e são analisados com base em pesquisa bibliográfica.

A escolha de trabalhar com narrativas de uma refugiada se justifica como busca de uma pesquisa mais reflexiva, a fim de ouvir e fazer ouvir a voz dessa mulher - o que permite, como observa Cunha (2013, p. 169), "uma abordagem interior", no relato de quem viveu o que narra, ainda que acreditemos que, como "são discursos construídos de maneira retrospectiva, um narrador pode contar diferentes histórias sobre si, em diferentes momentos, e também contar a mesma história para públicos diferentes (COSTA, 2018, p. 100).

Para a reflexão aqui apresentada, selecionamos as seguintes entrevistas concedidas por Mariama, dispostas abaixo em ordem cronológica:

3. The connection between women and migration bas slowly emerged as an area of research, and today forms a specific field of study that has been extensively explored by sociology, antbropology and geography, among other disciplines. 


\begin{tabular}{|c|c|c|c|c|}
\hline Referência & Título & Publicação & Ano & Duração \\
\hline N1 & $\begin{array}{l}\text { Mariama, refugiada da Gâmbia: 'Queria ser } \\
\text { uma mulher com a minha própria história' }\end{array}$ & ONU Brasil & $09 / 11 / 2016$ & $01: 40$ \\
\hline $\mathrm{N} 2$ & Entrevista refugiada Mariama Bah - TV Alerj & $\begin{array}{l}\text { PARES } \\
\text { Cáritas RJ }\end{array}$ & $26 / 05 / 2017$ & $03: 31$ \\
\hline N3 & $\begin{array}{l}\text { ONU reúne refugiados, autoridades e socie- } \\
\text { dade civil no Rio para debater crise humani- } \\
\text { tária global }\end{array}$ & ONU Brasil & $21 / 06 / 2017$ & $05: 21$ \\
\hline N4 & $\begin{array}{l}\text { Refugiados no Brasil, em Encontro com } \\
\text { Fátima Bernardes }\end{array}$ & Globoplay & $12 / 10 / 2017$ & 04:00 \\
\hline N5 & Mariama (Gâmbia) & Futura Play & 2017 & $11: 00$ \\
\hline
\end{tabular}

\section{REFUGIADOS NO BRASIL}

O movimento de solicitação de refúgio representa, em muitos casos, uma opção de sobrevivência para o solicitante. De acordo com a Convenção de 1951, da qual o Brasil é signatário, os proponentes de refúgio devem apresentar justificativas fundadas em temores de perseguição pela motivação de raça, religião, gênero ou opinião política, ou situações de violações de direitos. A convenção definiu e delimitou os direitos básicos que cada Estado deve garantir, sendo um dos principais a não expulsão e a não devolução dos mesmos quando sua vida e liberdade estejam em perigo. A aprovação do pedido de refúgio é dada pelo Comitê Nacional de Refugiados (doravante, CONARE) ${ }^{4}$.

A Lei de Refúgio brasileira - Lei 9474/1997 - garante o acolhimento de qualquer estrangeiro que solicite refúgio, desde o momento de sua chegada ao Brasil. A lei reafirma as definições estabelecidas na Convenção de 1951, na definição de refugiado e de não devolução, e garante aos refugiados os mesmos direitos de qualquer estrangeiro.

4. O CONARE é o órgão responsável por analisar os pedidos e declarar o reconhecimento, em primeira instância, da condição de refugiado, bem como por orientar e coordenar as ações necessárias à eficácia da proteção, assistência e apoio jurídico aos refugiados. 
Com a nova Lei de Migração - Lei n ${ }^{\circ} 13.445$ - sancionada em maio de 2017 e em vigor desde novembro do mesmo ano, o migrante tem garantia, em condição de igualdade com os nacionais, à inviolabilidade do direito à vida, à liberdade, à igualdade, à segurança e à propriedade. A legislação substitui o Estatuto do Estrangeiro, de 1980, com objetivo de oferecer uma abordagem mais compatível com o intenso fluxo migratório contemporâneo. A lei também institui o visto temporário para acolhida humanitária, a ser concedido ao apátrida ou ao nacional de país que, entre outras possibilidades, se encontre em situação de grave e generalizada violação de direitos humanos - situação que possibilita o reconhecimento da condição de refugiado, segundo a Lei $\mathrm{n}^{\circ} 9.474$, art. $1^{\circ}$, III.

A nova Lei de Migração, que proíbe distinções discriminatórias entre brasileiros e estrangeiros, entrou em vigor juntamente com a publicação do Decreto $n^{0}$ 9.199, que regulamenta diversos pontos da legislação e garante sua aplicação. Destaca-se que o normativo é resultado de debates entre órgãos governamentais e representantes da sociedade civil e de organismos internacionais. Com a não distinção entre estrangeiros e brasileiros, fica mais fácil a adesão às políticas públicas de educação, saúde e combate à miséria.

No Brasil, de acordo com os dados do relatório anual Refúgio em Números, emitido em 2018, havia 10.145 refugiados reconhecidos ao fim de 2017, de diversas nacionalidades, enquanto constavam mais de 80 mil solicitações de refúgio em trâmite. Recebemos migrantes de diversas nacionalidades, entre as nacionalidades que mais obtiveram reconhecimento de situação de refúgio entre 2007 e 2017 estão a Síria (2.771), República Democrática do Congo (953) e a Colômbia (316) (CONARE, 2018).

Em 2013, o país facilitou a entrada de refugiados sírios e simplificou a concessão de vistos, não exigindo comprovação de emprego fixo em seu país ou condições financeiras (Resolução Normativa $n^{0} 17$, prorrogada na Resolução Normativa $\mathrm{n}^{\mathrm{O}}$ 20, em 2015 por mais dois anos). Com essa medida, o Brasil passou a ser o país que mais recebeu refugiados sírios na América Latina nesse período.

A iniciativa posicionou o Brasil internacionalmente como um país aberto para o recebimento de refugiados sírios, no entanto, é importante ressaltar também a falta de programas específicos de ajuda financeira para refugiados. Sem renda, os estrangeiros são incluídos no programa Bolsa Família, que não faz distinção entre brasileiros e estrangeiros na distribuição de benefício financeiro mensal criado originalmente para retirar brasileiros da condição de miséria.

O Brasil teve um pico de solicitações de refúgio em 2015, com quase metade proveniente de haitianos. No entanto, análises revelaram que migrantes do Haiti 
não se enquadravam na categoria de refugiados e passou-se a conceder a eles o "visto humanitário", destinado a vítimas de crises econômicas e ambientais.

Hoje, destaca-se a situação de intenso fluxo migratório venezuelano em Boa Vista - RR, que se encontra em "situação de vulnerabilidade", conforme declaração do ex-presidente Temer, em 15 de fevereiro de 2018, devido à falta de estrutura para acomodar o fluxo de imigrantes da Venezuela. A entrada de venezuelanos pelas fronteiras do estado tem sido destaque na mídia por sua intensidade e pelo desafio estrutural que tem desenhado. Se em 2016 recebemos mais de 3.000 solicitações de refúgio por parte de venezuelanos, em 2017 esse número aumentou para 17.865.

À medida que o fluxo migratório aumenta, também se torna mais expressiva a presença feminina: em 2017, segundo dados do Comitê Nacional para os Refugiados (Conare), as mulheres representaram 30\% dos refugiados reconhecidos no Brasil. No perfil de refugiados reassentados 5 no Brasil, mulheres representam $46 \%$. Nos números globais, de acordo com o relatório Global Trends (UNHCR, 2018) elas representam $52 \%$ das pessoas em deslocamento forçado.

\section{SOBRE SER MULHER REFUGIADA}

Recentes estudos que buscam diferenciar os padrões migratórios conforme gênero e suas características locais reconhecem que o padrão tradicional, póscolonial, mais especificamente na segunda metade do século 20 e em direção à Europa, é majoritariamente formado por homens (CORTES, 2016, p 2). A invisibilidade de mulheres, tratadas por estudos na área referida como "feminização das migrações" (CORTES, 2016, MARINUCCI, 2007; MEJIA; CAZAROTTO, 2016), podem ser explicados pela ausência de mulheres no fluxo migratório (que muitas vezes ficavam no país de origem cuidando da casa e dos filhos enquanto maridos buscavam melhores oportunidades) e também pelo fato de muitos dados estatísticos não fazerem menção às diferenças de gênero nos números de migração.

Para Marinucci (2007), a "feminização das migrações" pode ser considerada a partir de três interpretações: a quantitativa, a de visibilidade e a qualitativa. A quantitativa faz jus aos números de imigrantes mulheres, que visivelmente vem crescendo. No entanto, esse fator sozinho não justificaria um estudo sobre o fenômeno: também é necessário considerar o enfoque de gênero que vem sendo pauta no debate internacional e atingindo maior visibilidade. Soma-se aos dois aspectos (que não são excludentes) a feminização qualitativa das migrações, um olhar

5. Reassentamento é a tranferência de refugiados para outro Estado que concordou em recebe-los. 
que considera a mudança de perfil das mulheres migrantes que buscam autonomia e emancipação através da migração. E em uma escala global, essa visibilidade, segundo Cortes (2016) vem crescendo desde os anos 1970 e se intensificando nas últimas duas décadas.

Se nos primeiros movimentos migratórios, na era pós-colonial, mulheres ou acompanhavam os maridos ou os esperavam em casa, na atualidade podemos encontrar mulheres como Mariama Bah. São mulheres que Cortes (2016) descreve como protagonistas de suas próprias histórias. A autora chama atenção, especificamente, para um novo olhar sobre a mulher que fica enquanto seu marido migra: não mais considerada uma mulher passiva e silenciada, mas uma mulher com autonomia, poder decisório e independência. Essa perspectiva se encaixa no que Marinucci (2007) define como mudança no perfil da mulher migrante, para quem a migração é consequência da emancipação. E é dentro desse perfil que ouvimos a voz que narra a história de Mariama Bah.

Nas entrevistas N1 e N2, Mariama enfatiza que decidiu sair de seu país por querer algo mais para sua vida além do matrimônio.

É por isso que eu quis conquistar meus sonhos, eu quis ser educada, eu quis ser uma mulher que, além de esposa, eu queria ser uma mulher de minha própria história, de conquistar meu próprio espaço. (N1)

Eu quero ser uma mulher que tenha profissão, que tenha voz. (N2)

Uma recente publicação da ONU no Brasil destaca a importância da educação de meninas refugiadas, mostrando os benefícios específicos da educação para elas. Ao reconhecer a maior vulnerabilidade de meninas em relação à violência sexual e de gênero, o artigo coloca a educação e o empoderamento como formas de resistência que criam possibilidades de diminuição de exploração e de aumento salarial. A agência indica que a educação "reduz a vulnerabilidade das meninas à exploração, violência sexual e de gênero, gravidez na adolescência e ao casamento infantil" (ONU, 2018). Instruídas, mulheres refugiadas sabem onde buscar a ajuda específica de que precisam.

Mariama conta que veio sozinha para o Brasil e fala sobre a decisão dos pais sobre o seu casamento, uma escolha tomada de acordo com os costumes, a religião e a cultura locais. Entre lágrimas, ela fala sobre ser mulher:

Você não tem voz [...], alguém tem que falar como você tem que viver, isso é muito difícil. (N2)

Eu quero ser uma mulher, além de esposa e mãe, que tenha profissão, que tenha voz. (N2)

Eu queria ter meu próprio destino, de ser uma mulher com minha própria voz fazer minha própria história. (N4) 
Pesquisas da UNESCO mostram que "mães instruídas têm maior probabilidade de matricular seus filhos na escola, especialmente suas filhas, e são mais propensas a apoiá-las a obter educação de nível secundário e superior" ${ }^{\prime \prime}$. Mariama conta, ao lado de sua filha, já no Brasil, o quão importante foi conseguir dar educação para a menina e evitar que ela passasse também pelo matrimônio infantil:

Eu queria que ela tivesse educação (no sentido escola), que ela fosse uma criança feliz, brincasse... e ela ter essa oportunidade de entender e saber o que é ser criança, que eu não tive (N4)

Hoje eu me sinto vitoriosa... vitoriosa não por acumular mestrados, doutorados ou uma conta no banco cheia de dinheiro, mas minha luta nos 10 anos, últimos anos, 10 anos, 11 anos... era o que eu queria conseguir para minha filha não passar pela mesma coisa que eu passei. Mas ela vai completar 14 anos, eu já era mãe nessa idade. E hoje está em uma escola, graças a Deus. (N3)

\section{POLÍTICAS DE LÍNGUA E CULTURA EM CONTEXTO DE REFÚGIO}

Muitos são os estudos que unem língua e cultura. De acordo com Laraia (2002, p. 52), a comunicação em si já é um processo cultural e, por termos domínio da linguagem, podemos transmitir conhecimento e criar um processo de acumulação de saberes. Assim, ele define que "a linguagem humana é um produto da cultura, mas não existiria cultura se o homem não tivesse a possibilidade de desenvolver um sistema articulado de comunicação oral".

Dominar a língua do país de acolhimento, no caso de refúgio, apresenta-se como uma necessidade e não uma escolha. Desde a chegada no Brasil, solicitantes de refúgio enfrentam barreiras linguísticas que se impõem pela falta de profissionais multilíngues nos postos de fronteira, como aeroportos e terminais rodoviários, o que causa um abismo entre a comunicação do interceptor e do receptor (PEREIRA, 2017). Tais barreiras têm impacto recorrente em suas vidas, na busca por oportunidades de trabalho, de acesso à educação, à saúde e outros serviços públicos.

No Brasil, com o aumento do fluxo migratório, fica clara a necessidade de mais estrutura nos pontos de entrada e contato com imigrantes.

[...] o movimento de pessoas traz consigo o movimento de línguas. Assim, o crescimento exponencial da mobilidade humana teve como resultado mudanças no cenário linguístico dos Estados-nação [...]. Frente a esse inevitável mosaico linguístico os Estados [...] precisam responder ao desafio de atender à diversidade de línguas trazidas pelos sujeitos que as falam. (OLIVEIRA; SILVA, 2017, p. 133)

6. ONU, Por que educar meninas refugiadas? Publicado em 14/08/2018. Disponível em: https://www. acnur. org/portugues/2018/08/14/por-que-educar-meninas-refugiadas/ 
Em 2015, o Instituto de Pesquisa Econômica Aplicada (IPEA) pesquisou entre instituições de acolhimento, imigrantes, solicitantes de refúgio e refugiados a fim de refletir sobre as principais dificuldades que se apresentam a imigrantes no Brasil, considerando o acesso à efetivação de seus direitos. Tendo em vista o aumento no fluxo de imigração para o Brasil, o estudo teve por objetivo compreender melhor a dinâmica e as necessidades da mobilidade humana nesse contexto, com vistas a melhorar o acolhimento aos imigrantes. Segundo o relatório, dentre as dificuldades que são enfrentadas, o idioma apareceu em primeiro lugar como obstáculo para o acesso a direitos e/ou serviços, seguido dos itens documentação e falta de informação. $\mathrm{O}$ estudo indica que apenas $21 \%$ dos imigrantes declararam falar o português no momento da solicitação de refúgio, enquanto os idiomas mais falados são o árabe, o inglês, o francês, o espanhol e o lingala (língua falada na República Democrática do Congo).

É a professora Simone de Almeida que nos relata como foi o início das aulas de Mariama, pela Cruz Vermelha, em Nova Iguaçu/Rio de Janeiro:

E a Mariama não falava quase nada de português (risos). E eu falava umas coisas e ela não entendia, e eu ia por mímica, e ia voltando, e tinha alguma coisa que ela só entendia em inglês, não tinha nada na terra dela com a palavra. (N5)

A falta de políticas linguísticas tem grande impacto quando se trata de solicitantes de refúgio. Essas barreiras são um problema comum para quem chega e para quem recebe, causando mal-entendidos e preconceitos (PEREIRA, 2017; GROSSO 2010). A aprendizagem da língua e da cultura do país no qual os refugiados buscam inserção é de extrema importância, ressalta Grosso (2007), muito diferente do que acontece com alunos que buscam um idioma como segunda língua por escolha (pessoal ou profissional). E é marcada como "barreira" que a questão aparece na fala de Mariama:

\footnotetext{
A primeira barreira que a gente tem é aquele idioma. Imagina, de dia para o outro você tem que falar... nem todo mundo fala inglês. Existem muitas pessoas aqui que falam inglês, mas a maioria não fala. Então diariamente, você querendo se comunicar ou falar com alguém e você não fala o idioma. (N5)
}

A comunicação é essencial para a melhoria da qualidade de vida e para a integração dos refugiados e aprender a língua do país é uma questão ligada à sobrevivência. O idioma se apresenta como uma forma (muitas vezes a única) de acesso a direitos e oportunidades, uma vez que todos os dias "[...] barreiras linguísticas impedem que centenas de imigrantes tenham acesso a serviços públicos básicos como saúde e educação" (OLIVEIRA; SILVA, 2017, p. 132). Tratando-se de 
grupos em situação de vulnerabilidade, como é o caso de refugiados, concordamos com a análise de que barreiras linguísticas fragilizam severamente o acesso a direitos humanos, pois, a partir de "perspectiva legal baseada nos princípios dos direitos humanos, quando uma situação envolve desvantagens ou discriminações significativas, serviços de tradução e interpretação devem ser oferecidos" (OLIVEIRA; SILVA, 2017, p. 135).

Nesse contexto, aprender um novo idioma significa "uma nova categoria de investigação que diz respeito às condições necessárias para o aprendizado da língua, para além da proficiência: a sobrevivência do refugiado no país que o acolhe" (PEREIRA, 2017, p. 119). É considerando o cenário de ensino para refugiados que atualmente se discute a especialidade de ensino de Português como Língua de Acolhimento (doravante, PLAc), que ressalta o domínio do idioma no sentido de acolhimento literal e poderosa via para a integração social (ANÇÃ, 2008; PEREIRA, 2017).

No que tange ao aprendizado, o objetivo do PLAc não é unicamente a competência comunicativa através do idioma, mas também a necessidade de adaptação rápida à nova realidade linguístico-cultural. Para esse fim, considera-se que é através do "estudo da língua portuguesa que o refugiado pode se manifestar e se assegurar efetivamente" (PEREIRA, 2017, p. 128). Para tanto, o aprendizado da língua também passou a ser repensado levando em consideração esse público específico constituído de diferentes gêneros, idades e formação e provenientes de diferentes grupos linguísticos, a considerar pela diversidade de línguas faladas pelos refugiados, muitas vezes falantes plurilíngues.

Por exemplo, na Gâmbia, de colonização britânica, o inglês é o idioma oficial e o país ainda tem cinco línguas nacionais reconhecidas: mandinka, fula, wolof, serer e jola. Mariama explica que nem todos falam inglês, o que também pode ser uma barreira comunicativa, mas quando você viaja no contexto de refúgio, somam-se outras dificuldades:

Entrando em um país, você não tem emprego, você não tem família. É outra coisa. Você não conhece ninguém. Então, dificuldades, tiveram muitas. (N5)

A abordagem metodológica dentro do PLAc também prevê diferentes particularidades no ensino, quanto ao planejamento, material didático, objetivos comunicativos que deem conta da diversidade linguística e cultural dos alunos. Os estudos nessa linha reconhecem a importância de conhecer a cultura do país em que os refugiados estão vivendo, bem como a importância de ter sua cultura de origem valorizada. Além de considerar a cultura de origem, o planejamento das aulas passa 
por tópicos que exploram as necessidades diárias dos alunos, como documentação necessária no Brasil, funcionamento do transporte público, busca por emprego, matrícula de filhos em escola e atendimento em postos de saúde.

Além da reivindicação por necessidade básicas, é com o domínio do idioma que o refugiado passa a ter maior acesso também à nova cultura com a qual se depara e pode dialogar com costumes, tradições e valores do país de acolhimento. É vivendo mudanças culturais que, diz Laraia (2002), os homens se tornam capazes de reconhecer e de, até mesmo, questionar seus próprios hábitos. É nesse contexto que pode haver um diálogo entre a cultura de origem e a cultura na qual o refugiado está sendo inserido, e de maneira reflexiva. Nas entrevistas de Mariama Bah, percebemos o carinho por seu país de origem, para o qual ela diz que sonha em voltar, junto com o questionamento sobre o aspecto cultural que a fez migrar: o matrimônio infantil.

Ela demonstra, nas suas falas, o carinho que tem pela cultura do seu país:

Eu venho de uma etnia de pessoas muito boas, muito trabalhadoras (N1)

$\mathrm{O}$ lugar mais bonito do mundo é onde você nasceu. (N2)

Mas, também conta que foi necessário impor-se para ir contra aquilo em que ela não acreditava:

Eu quis estudar muito, o que não batia muito com nosso costume, que a gente tinha lá. (N1) [...] cresci e não concordava com isso, porque é cultura não quer dizer que todo mundo tem que obedecer isso (N4)

Mesmo quando ela se refere especificamente ao casamento infantil, ela reconhece como uma cultura do seu país:

[...] para eles (os pais), é parte de religião, parte de costume também, cultura. (N2)

Em diversos momentos a emoção é forte e ela se emociona. Ao falar das privações, ela não controla as lágrimas e desabafa:

Para ser mulher e você querer ter caráter de ir adiante, é muito difícil, porque eles não deixam. Você é uma escrava, você não tem voz. Você não pode falar dos seus sentimentos, você não escolhe a vida que você quer viver. (N2)

Quando ela é questionada pela entrevistadora - se isso é normal na Gâmbia -, Mariama é crítica e também expõe que outras mulheres de sua família passam pela mesma situação: 
[...] eu acho que não é normal... a gente vive isso e tem pessoas que eles não gostam, mas não têm coragem de tomar uma iniciativa de dizer 'basta, eu não quero isso'. Por exemplo, na minha família eu tenho minhas tias, ninguém tem escolarização. Eu sou a primeira mulher que está lutando para mudar, para ter educação. (N2)

O comportamento reproduzido na sua comunidade e questionado por Mariama Bah, mostra que cultura é um aprendizado, um processo a que Laraia (2002) se refere como endoculturação: "um menino e uma menina agem diferentemente não em função de seus hormônios, mas em decorrência de uma educação diferenciada" (LARAIA, 2002, p. 20).

E sobre a vida no Brasil, ela afirma:

Eu acho que uma das coisas que eu gostei aqui é aquela liberdade de você ser quem você quer ser. Se você quer, você consegue ser. Isso é muito bom. (N5)

Ao mesmo tempo em que elogia a solidariedade carioca, ela faz a ressalva:

Obviamente, eu não estou falando que não existe preconceito. Existe. Não estou falando que é tudo maravilha, também existe lado ruim. Mas para quem abre o coração e quer uma pessoa para te abraçar, também existe pessoas que te abraçam. Eu acho isso aqui muito bom. (N5)

\section{CONSIDERAÇÕES FINAIS}

As narrativas de Mariama Bah são expostas não para uma análise de um indivíduo específico: ela representa um membro de um "grupo cultural" e, a partir dela, buscamos refletir sobre a situação de refugiadas dentro de um contexto contemporâneo de migração: "dessa história se depreende o comum do individual, o geral do particular" (CUNHA, 2013, p. 169).

Como ponto de partida, caracterizamos o perfil dos imigrantes que solicitam refúgio no Brasil, para, em seguida, ressaltarmos o recorte de gênero nesse contexto, ao mesmo tempo em que buscamos ressaltar a língua e a cultura no processo de integração de refugiados no Brasil. As palavras de Mariama, tão atuais no contexto de imigração, representam a voz de uma mulher que escolheu buscar igualdade fora do seu país.

No âmbito linguístico, refletimos sobre o papel do idioma no acesso a políticas públicas e no exercício de cidadania, tendo o português como língua de acolhimento e integração para refugiados. O domínio da língua dá acesso a conhecimento, ao exercício da cidadania, à voz de defesa. Com acesso a informação, acreditamos que mulheres entendem os instrumentos também para denunciar assédios, discriminação e violências, de gênero ou não. 
Sabemos que fatores que não linguísticos também afetam a integração de um refugiado, que se encontra submetido "a um conjunto de pressões econômicas, sociais e legais que o colocam em uma posição de vulnerabilidade" (BARBOSA; RUANO, 2016, p. 323). Aprender um idioma totalmente novo é uma urgência conforme suas necessidades de interação no país. Buscará acesso a políticas públicas e precisará vencer barreiras linguísticas, burocráticas, financeiras ou de preconceitos.

Ao olharmos a situação das mulheres, também podemos adicionar que é necessário superar desigualdades e violências de gênero, buscar independência e autonomia. Mulheres que migram em busca de quebrar ciclos e questionar tradições culturais.

A diversidade de refugiados que procuram acolhimento no Brasil forma o que Oliveira e Silva (2017) chamam de mosaico linguístico, um contexto que acabar por propiciar situações de intenso contato linguístico e cultural a cada necessidade de interação. É também através do idioma que refugiados e refugiadas podem compartilhar sua história, sua origem e seus costumes, assim: "eles acrescentam novas visões à vida, trazem vivências e costumes de uma outra bagagem histórica e social. Estamos apenas tratando de assimilar diferenças - atitude que toda sociedade que preze pela cidadania deve fazer" (PEREIRA, 2017, p. 130).

Acreditamos na riqueza da pluralidade cultural que acompanha a imigração, a partir do compartilhamento de culturas, aprendizado de novas realidades e de novos idiomas. A escolha da mulher refugiada em evidência neste trabalho foi uma pensada a fim de trazer visibilidade de gênero no contexto de refúgio, condizente com os estudos de feminização das migrações, aspecto que em diversos campos e esferas da sociedade, ainda é silenciado. Mariama segue contando sua história, lutando por mais educação para mulheres:

Apesar de tudo o que a gente passa, a gente é muito mais que isso. Qualquer menina africana, ou de qualquer parte do mundo, se você enxerga que pode fazer alguma diferença, não espere, lute. E, sabe, não vai ser nada fácil, mas a satisfação de vencer é muito maior que as dores. (N1)

Desejamos que as vozes de refugiadas sejam cada vez mais ouvidas e respeitadas, e que, no país onde buscaram refúgio, possam viver trajetórias de acolhimento, e não de discriminação.

\section{REFERÊNCIAS}

ALTO COMISSARIADO DAS NAÇÕES UNIDAS PARA OS REFUGIADOS (ACNUR). Global Trends: Forced Displacement 2015. Genebra, Suíça: ACNUR, 2018 Disponível em: 
$<\underline{\text { http:} / / w w w . u n h c r . o r g / 576408 c d 7 \# ~ g a ~}=1.218846928 .879996130 . \quad 1483964323>$ Acesso em 15 de jul. De 2018.

\section{ALTO COMISSARIADO DAS NAÇÕES UNIDAS PARA OS REFUGIADOS} (ACNUR). Dados sobre refúgio no Brasil - Balanço até abril de 2016. Brasília: ACNUR Brasil, 2016b. Disponível em: <http://www.acnur.org/portugues/recursos/estatisticas/ dados-sobre-refugio-no-brasil//>Acesso em 20 de jul. de 2018.

ANÇÃ, M. H. (2008). Língua portuguesa em novos públicos. Saber (e) Educar. Porto, n. 13, p. 71-87. Disponível em: http://repositorio.esepf.pt/handle/20.500.11796/924. Acesso em: 20 julho 2018.

BANDEIRA, Luzia. (2018). Sem programa específico para refugiados, Brasil põe centenas de sírios no Bolsa Família. BBC Brasil. Disponível em: http://www.bbc.com/ portuguese/ noticias/2015/10/151013_bolsa_familia_sirios_lab. Acesso em 15 outubro de 2018.

BARBOSA, Lúcia Maria de A.; RUANO, Bruna P. (2016). Acolhimento, sentidos e práticas de ensino de português para migrantes e refugiados, na Universidade de Brasília e na Universidade Federal do Paraná. In: GEDIEL, José A. P.; GODOY, Gabriel G. de (Org.). Refúgio e Hospitalidade. Curitiba: Kairós Edições.

CÁRITAS. (2018). Disponível em $<\underline{\text { http: } / / w w w . c a r i t a s-r j . o r g . b r / t r a b a l h e c o n o s c o . h t m l ~}>$ Acesso em: 01 de ago. de 2018.

COMITÊ NACIONAL PARA OS REFUGIADOS (CONARE). (2018). Ministério da Justiça. Refúgio em Números - $3^{a}$ ed. Brasília. Disponível em: $<\underline{\text { http://www.justica. gov. }}$ br/news/de-10-1-mil-refugiados-apenas-5-1-mil-continuam-no-brasil/refugio-emnumeros 1104.pdf >. Acesso em: 15 jul. 2018.

CORTES, Geneviève. (2016). Women and Migrations: Those Who Stay, EchoGéo, n. 37. Disponível em: http://echogeo.revues.org/14892.

COSTA, Débora. (2018). Negociação de identidades e formação de novas representações sociais em narrativas de migração: uma proposta metodológica. Tese de Doutorado. Programa de Pós-graduação em Estudos de Linguagem, Universidade Federal Fluminense, Niterói.

CUNHA, Maria Jandyra Cavalcanti. (2013). Comunicação e identidade cultural na língua de imigração. In: SILVA, Kleber; SANTOS, Danúsia Torres dos (Orgs.), Português como língua (inter)nacional: faces e interfaces. Campinas, SP: Pontes Editores. 
GROSSO, M. J. R. (2010). Língua de acolhimento, língua de integração. Horizontes de Linguística Aplicada, v. 9, n.2, p. 61-77.

LARAIA, Roque de Barros. (2002). Cultura, um conceito antropológico. Rio de Janeiro, Jorge Zahar Editor Ltda. 2002.

LUSSI, Carmem. (2015). Políticas públicas e desigualdades na migração e refúgio. Psicologia USP, v. 26, n. 2, pp. 136-144. Disponível em: http://www.scielo.br/pdf/pusp / v26n2/0103-6564-pusp-26-02-00136.pdf

OLIVEIRA, Gilvan Müller de; SILVA, Julia Izabelle da. (2017). Quando barreiras linguísticas geram violação de direitos humanos: que políticas linguísticas o Estado brasileiro tem adotado para garantir o acesso dos imigrantes a serviços públicos básicos? Gragoatá: Revista dos Programas de Pós-Graduação do Instituto de Letras da UFF, Niterói, v.22, n. 42, p. 131-153, jan./abr. Disponível em: http://www.gragoata.uff.br/ index. php/gragoata/article/view/909/636. Acesso em: 10 abr. 2018.

ONU. (2018). Agência da ONU enfatiza importância de garantir educação de meninas refugiadas. Publicado em 15/08. Disponível em: https://nacoesunidas.org/agenciada-onu-enfatiza-importancia-de-garantir-educacao-de-meninas-refugiadas/

PEREIRA, Giselda F. (2017). O português como língua de acolhimento e interação: a busca pela autonomia por pessoas em situação de refúgio no Brasil. São Paulo, Cadernos de Letras, v. 17, n. 1 .

\section{REFERÊNCIAS DE VÍDEOS ONLINE}

N1: Mariama, refugiada da Gâmbia: 'Queria ser uma mulher com a minha própria história'. ONU BRASIL. Brasil, publicado em 9 de nov de 2016. Disponível em https://youtu. be/hWNNCaV-sFw $(1 \mathrm{~m} 40)$

N2: Entrevista refugiada Mariama Bah - TV Alerj. PARES Cáritas - RJ. Brasil, publicado em 26 de maio de 2017. Disponível em https://youtu.be/LxjYRRpuGcs (3m31)

N3: ONU reúne refugiados, autoridades e sociedade civil no Rio para debater crise humanitária global. ONU BRASIL. Brasil, publicado em 21 de jun de 2017. Disponível em https://www.youtube.com/watch?v=EWa3EuU0iFU (05m21)

N4: Refugiados no Brasil, em ENCONTRO COM FÁTIMA BERNARDES. Globoplay. Brasil. Disponível em: https://globoplay.globo.com/v/6212493/. Exibição em 12 out 2017. (4 min) 
N5: Mariama (Gâmbia). Futura Play. Brasil, publicado em 2017. Disponível em: http://www. futuraplay.org/video/mariama-gambia/396243/ (11m)

Recebido: 24/11/2018

Aceito: 31/07/2019

Publicado: 13/08/2019 